\title{
Prevalence and factors associated with preoperative anxiety in children aged 5-12 years $^{1}$
}

\author{
Louise Amália de Moura² \\ Iohanna Maria Guimarães Dias ${ }^{3}$ \\ Lilian Varanda Pereira ${ }^{4}$
}

\begin{abstract}
Objective: to estimate the prevalence and factors associated with preoperative anxiety in children who wait for outpatient surgery. Method: cross-sectional analysis of baseline data of a prospective cohort study that investigates the predictors of postoperative pain in children aged 5-12 years submitted to inguinal and umbilical hernia repair. It was selected 210 children, which were interviewed in the preoperative holding area of a general hospital. Anxiety was evaluated using the modified Yale Preoperative Anxiety Scale (mYPAS). Sociodemographic and clinical variables were analyzed as exposure and anxiety (mYPAS final score $>30$ ) as outcome. Logistic regression was used to identify factors associated with preoperative anxiety. Results: forty-two percent $(42.0 \%)$ of children presented preoperative anxiety (CI95\%: 35.7\%-48.6\%), with mean scores equal to $30.1(S D=8.4)$. Factors associated with preoperative anxiety were: age group of $5-6$ years $(O R=2.28 ; p=0.007)$ and socioeconomic status classified as class $C(O R=2.39$; $p=0.016)$. Conclusion: the evaluation of children who wait for outpatient surgery should be multidimensional and comprise information on age and socioeconomic status, in order to help in the identification and early treatment of preoperative anxiety.
\end{abstract}

Descriptors: Anxiety; Child; Child, Preschool; Preoperative Period; Ambulatory Surgical Procedures; Pediatric Nursing.

\footnotetext{
${ }^{1}$ Paper extrated from Master's Thesis "Incidence and predictors of postoperative pain in children undergoing outpatient surgeries in Goiania, GO, Brazil: a cohort perspective", presented to Faculdade de Enfermagem, Universidade Federal de Goiás, Goiânia, GO, Brazil.

2 MSc, Assistant Professor, Faculdade de Enfermagem, Universidade Federal de Goiás, Goiânia, Go, Brazil.

3 Undergraduate student in Nursing, Faculdade de Enfermagem, Universidade Federal de Goiás, Goiânia, GO, Brazil.

${ }^{4}$ PhD, Adjunct Professor, Faculdade de Enfermagem, Universidade Federal de Goiás, Goiânia, Go, Brazil.
}

Moura LA, Dias IMG, Pereira LV. Prevalence and factors associated with preoperative anxiety in children aged 5-12 years. Rev. Latino-Am. Enfermagem. 2016;24:e2708. [Access_ _ ] ; Available in: $\left.\right|_{1}$. DOI: http://dx.doi.org/10.1590/1518-8345.0723.2708 ${ }^{\text {month }}$ day year 


\section{Introduction}

Anxiety is a common feeling among children in the preoperative period(1-4). As acute stress source, anxiety induces functional changes in the central nervous system, increases the deleterious effects on the child's body when associated with other perioperative stressors $^{(5)}$, produces negative behaviors ${ }^{(4,6-8)}$ and high pain intensity scores in the postoperative period ${ }^{(1,4,9)}$. In addition, anxiety causes sleep disruption, nausea, fatigue, and inadequate responses to anesthesia and analgesia(1,9), leading to higher costs for the health services and family.

In the immediate preoperative period, which corresponds to 24 hours before surgery, discomfort is imminent for the children and their family, regardless of the type of surgery, outpatient or hospital approach and cultural context in which the child is inserted(10). In addition, the susceptibility of the child, lack of understanding about the surgical procedure, unknown hospital environment, fear of physical injury, separation from their parents ${ }^{(11)}$ and feelings of sadness and punishment related to the fact that surgery is a scheduled procedure may contribute to such discomfort ${ }^{(12)}$.

Several evidence indicate age $\mathrm{e}^{(2-3,13-15)}$ and temperament ${ }^{(3)}$ of the child, behavioral problems during health care ${ }^{(15)}$, previous surgery and hospitalizations ${ }^{(4,15)}$, level of parental education and maternal anxiety $y^{(1,3,16)}$ as factors associated with preoperative anxiety in children.

In the case of outpatient surgery, however, there are still knowledge gaps on the prevalence and factors associated with this psychological phenomenon in children. This possibly because parents and children remain together for a short period in the hospital setting and there is little availability of health professionals to provide an individualized and comprehensive care, including the multidimensional evaluation of the child in the preoperative period. It has been emphasized that the identification of children at risk might promote the use of preventive strategies and avoid problems caused in the postoperative recovery when anxiety remains at unacceptable levels. The aim of this study was to estimate the prevalence and factors associated with preoperative anxiety in children who wait for outpatient surgery.

\section{Methodology}

This is a cross-sectional analysis of baseline data of a prospective cohort and open study, developed in Goiania, Brazil. Children were hospitalized for elective outpatient surgery, from April/2013 to February/2014.

\section{Participants}

It was eligible for this study children of both sexes, aged 5-12 years, with indication of elective surgeries for umbilical and inguinal hernia repair, of outpatient basis (maximum of 24 hours of hospital stay), single-port (less than two-hours procedure) and ASA I and II for operative risk. According to the scale of the American Society of Anesthesiologists (American Society of Anesthesiology) (ASA) (www.asahq.org/clinical/physicalstatus.htm), the classification of the physical status considers healthy patients as ASA I, and patients with mild to moderate systemic disease without functional limitation as ASA II.

Exclusion criteria for children were: be forwarded directly to the surgical room, which prevented preoperative contact; need to stay in the hospital for more than 24 hours, mischaracterizing ambulatory surgical care; make use of anxiolytic drugs at preoperative period; and non-attendance for surgery as scheduled. At the end of 10 months, 210 children were included in the sample.

\section{Study site}

Analysis of data from the Hospital Information System of SUS of Ministry of Health, in 2012, showed that nine ${ }^{(9)}$ hospitals in the city of Goiania performed pediatric ambulatory surgeries $(n=291)$. Among children aged $5-12$ years, $89 \%$ of the surgeries occurred in a general care hospital, $7.5 \%$ occurred in a pediatric hospital and $3.5 \%$ in other hospitals. Therefore, it was decided to select for this study, data of children assisted in the hospital with the highest number of visits in this municipality, and in this place, only a pediatric surgeon was the responsible for the surgical care provided.

\section{Data collection}

Data collection was carried out by two nurses qualified for the evaluation of anxiety, before surgery, in the preoperative holding area. Sociodemographic and economic data were collected from those responsible for the child. The assessment of anxiety and preoperative pain occurred through direct observation and child's report. The intensity of the preoperative pain was measured using a scale of faces printed. To evaluate preoperative anxiety, the observer was dressed in an ordinary outfit to avoid "anxiety" associated with white clothes.

\section{Study variables}

Outcome variable

- Preoperative anxiety - measured using the modified Yale Preoperative Anxiety Scale - mYPAS, translated and validated into Brazilian Portuguese ${ }^{(17)}$. 


\section{Exposure variables}

- Socio-demographic: age of the child (5-6 years and 7-12 years); sex (male and female) and socioeconomic status (classified as class $A$ ( $\mathrm{A} 1$ and $A 2$ classes), class $B$ (B1 and B2 classes), class C ( 1 1 and C2 classes), class D (Class D) and class E (class E), according to the Brazilian Economic Classification Criterion $(\mathrm{CCEB})^{(18)}$. This criterion takes into account the sum score regarding the education level of the household head and the scores of objects that the family has to determine the economic class. Class A represents the highest socioeconomic status, whereas class E represents the lowest.

- Clinics: previous surgery (yes and no), previous hospitalization (yes and no) and preoperative pain (yes and no).

\section{Instruments used}

Preoperative anxiety was evaluated using the modified Yale Preoperative Anxiety Scale - mYPAS(17), observational measurement, which was planned for use in children in the immediate pre-anesthetic period and at the time of anesthetic induction. The YPAS was developed and later modified - mYPAS (Yale Preoperative Anxiety Scale modified) by Kain et al. (1997)(19). This scale has 27 items distributed in five areas of behavior that include the child's relationship with the environment in which they are, as follows: domain 1 - activities (with 4 categories); 2 - vocalization (with 6 categories); 3 - emotional expressiveness (with 4 categories); 4 - state of awakening (with 4 categories) and 5 - interaction with family members (with 4 categories). A partial score is assigned for each domain based on the observed score, and this score is added to those of other domains, which is then multiplied by 20 . The presence of anxiety is identified when the sum exceeds 30 points. The study that has adapted the mYPAS into Portuguese showed high reliability indexes (Cronbach's alpha values between 0.88 and 0.95 ; Spearman coefficients between 0.44 and 0.95; Kappa between 0.79 and 1.00 and Guttmann's coefficient between 0.63 and 0.90 ), considering the scale as reliable and reproducible(17).

The intensity of preoperative pain was measured using the Faces Pain Scale-Revised (FPS-R) ${ }^{(20)}$, designed for children from 4 years of age. The FPS-R is a six- point scale with faces indicating increasing intensity. The leftmost face is indicative of absence of pain, and the following faces express increasing intensity until the rightmost face, which signals great pain, enabling the child to quantify their painful experience. The psychometric properties of the FPS-R were tested and the original version has been translated into 35 languages (www.painsourcebook.ca). It has been used in many clinical trials, demonstrating the possibility of identifying pain and pain relief achieved through analgesic therapy. For this study, it was used the Brazilian Portuguese version and the score 0-2-4-6-810 was adopted to quantify the respective six (6) faces of the scale ${ }^{(21)}$.

\section{Data analysis}

Here, it was decided to present the categorical variables as absolute and percentage values. The preoperative anxiety outcome was described as mean and standard deviation, with cutoff set as greater than 30 points for the overall score of the mYPAS. The prevalence of anxiety was estimated with confidence interval of $95 \%$, and regression was used for the bivariate and multivariate analyzes. The multivariate model included variables with $p \leq 0.10$ in the bivariate analysis. All $p$-values less than $0.05(p<0.05)$ were considered as statistically significant.

\section{Results}

Among the 229 children scheduled for outpatient surgery, 19 (8.2\%) were excluded from the study: nine (9) because they were forwarded directly to the operating room and 10 due to non-attendance in the day of surgery. Thus, the final sample consisted of 210 children.

There was a prevalence of male children, aged 7-12 years and belonging to the socioeconomic status previously described and classified as Class C. Most of them had not experienced previous hospitalization or surgery and waited for inguinal hernia repair (Table 1).

In the preoperative holding area, $11.4 \%$ of children reported pain at the site of the hernia to be repaired, with an average intensity score equal to 4.25 $(\mathrm{SD}=2.5)$. 
Table 1 - Distribution of children, according to sociodemographic and clinical variables. Goiania, GO, Brazil, 2013-2014

\begin{tabular}{lcc}
\hline \multicolumn{1}{c}{ Variables } & \multicolumn{2}{c}{ Children $(\mathbf{n}=\mathbf{2 1 0})$} \\
\cline { 2 - 3 } Gender & $\mathbf{n}$ & $\%$ \\
Female & 100 & 47.6 \\
Male & 110 & 52.4 \\
Age group & & \\
5-6 years & 87 & 41.4 \\
7-12 years & 123 & 58.6 \\
Socioeconomic status & & \\
Class B & 45 & 21.5 \\
Class C & 125 & 59.5 \\
Class D & 40 & 19.0 \\
Previous hospitalization & & \\
Yes & 93 & 44.3 \\
No & 117 & 55.7 \\
Previous surgery & & \\
Yes & 30 & 14.3 \\
No & 180 & 85.7 \\
Preoperative pain & & \\
Yes & 24 & 11.4 \\
No & 186 & 88.6 \\
Surgery type & & 31.0 \\
Inguinal hernia repair & 145 & \\
Umbilical hernia repair & 65 & \\
\hline
\end{tabular}

It was observed a prevalence of preoperative anxiety of $42.0 \%$ (CI95\%: $35.7 \%-48.6 \%$ ), with average anxiety score of $30.1(S D=8.4)$, according to the mYPAS.

In the bivariate analysis, the factors associated with preoperative anxiety included the age group 5-6 years $(O R=2.16)$ and socioeconomic class $C(O R=2.27)$ (Table 2).

After adjusting, gender, age group of 5-6 years and socioeconomic class $\mathrm{C}$ remained associated with preoperative anxiety. Children with these characteristics were twice as likely to present preoperative anxiety (Table 3).

Table 2 - Potential factors associated with preoperative anxiety, according to sociodemographic and clinical characteristics of children. Goiania, GO, Brazil, 2013-2014

\begin{tabular}{|c|c|c|c|c|c|c|}
\hline \multirow{2}{*}{$\begin{array}{l}\text { Sociodemographic and clinical } \\
\text { characteristics }\end{array}$} & \multicolumn{2}{|c|}{ Preoperative anxiety } & \multirow{2}{*}{$\beta^{*}$} & \multirow{2}{*}{$\mathrm{OR}^{\dagger}$} & \multirow{2}{*}{$\mathrm{Cl}(95 \%)^{\ddagger}$} & \multirow{2}{*}{$p^{\S}$} \\
\hline & $\mathbf{N}$ & $\%$ & & & & \\
\hline \multicolumn{7}{|l|}{ Gender } \\
\hline Female & 41 & 46.6 & -0.07 & 0.93 & $0.53-1.61$ & 0.800 \\
\hline Male & 47 & 53.4 & & & & \\
\hline \multicolumn{7}{|l|}{ Age group } \\
\hline $5-6$ years & 46 & 52.3 & 0.77 & 2.16 & $1.23-3.79$ & 0.007 \\
\hline $7-12$ years & 42 & 47.7 & & & & \\
\hline \multicolumn{7}{|l|}{ Socioeconomic status } \\
\hline Class B & 26 & 29.6 & & & & \\
\hline Class C & 47 & 53.4 & 0.82 & 2.27 & $1.13-4.54$ & 0.020 \\
\hline Class D & 15 & 17.0 & 0.82 & 2.28 & $0.95-5.45$ & 0.064 \\
\hline \multicolumn{7}{|l|}{ Previous hospitalization } \\
\hline Yes & 44 & 50.0 & 0.39 & 1.49 & $0.85-2.59$ & 0.158 \\
\hline No & 44 & 50.0 & & & & \\
\hline \multicolumn{7}{|l|}{ Previous surgery } \\
\hline Yes & 16 & 18.2 & -0.53 & 0.58 & $0.26-1.26$ & 0.174 \\
\hline No & 72 & 81.8 & & & & \\
\hline \multicolumn{7}{|l|}{ Preoperative pain } \\
\hline Yes & 10 & 11.4 & -0.01 & 0.98 & $0.41-2.34$ & 0.980 \\
\hline No & 78 & 88.6 & & & & \\
\hline
\end{tabular}


Table 3 - Factors associated with preoperative anxiety. Goiania, GO, Brazil, 2013-2014

\begin{tabular}{rcccc}
\hline Variables & $\boldsymbol{\beta}^{*}$ & $\mathrm{OR}_{\text {adjust }}{ }^{\dagger}$ & $\mathrm{Cl}(95 \%)^{\ddagger}$ & $\mathrm{p}^{\S}$ \\
\hline Age group of 5-6 years & 0.82 & 2.28 & $1.25-4.16$ & 0.007 \\
Socioeconomic class C & 0.87 & 2.39 & $1.17-4.87$ & 0.016 \\
\hline
\end{tabular}

*Beta coefficient

+Odds Ratio adjusted by gender

$\neq$ Confidence interval of $95 \%$

§Significance level

\section{Discussion}

The results of this study demonstrate that many children who wait for outpatient surgery experience preoperative anxiety. Factors such as age and socioeconomic status influence the occurrence of this phenomenon.

It was observed that $42.0 \%$ of children were anxious in the preoperative holding area of the hospital. Brazilian researchers estimated a high prevalence (81.6\%) of anxiety among children ( $4.67 \pm 0.96$ years) weeks prior to surgery, at the time of outpatient preoperative evaluation $^{(22)}$. In the evaluation of children aged 4-8 years, prevalence rates of $38.9 \%{ }^{(23)}$ and $84.0 \%{ }^{(24)}$ were found in the preoperative holding area.

Before surgery, the child tends to understand this event as a threat that, in just few minutes, causes different feelings ${ }^{(12)}$. Contradictory prevalence of preoperative anxiety may be related to the age of the children ${ }^{(22-24)}$, anxiety measurement instrument ${ }^{(19)}$, lack of information about the surgery to be performed, separation from their parents ${ }^{(10)}$ and previous experience in health care ${ }^{(3-4)}$.

In this study, for example, after discharge from the post-anesthetic recovery room, the children returned to the same preoperative holding area. It is very likely that those waiting for the time to enter the operating room tended to express higher levels of fear and anxiety because they saw post-operated children distressed or crying. High levels of anxiety impair the recovery of children, and subsequently affect the physical and psychological health, impair the ability to deal with medical treatment and generate negative behavior regarding future health cares $^{(1,4,7-9)}$.

Currently, in order to prevent the effects of this situation, preoperative preparation programs including the participation of children and their parents, before and after surgery, have been proposed(11,25-26).

In this sense, the first move is the identification of children at risk. Age is a factor that interferes in the occurrence of anxiety in the preoperative period, a finding consistent with those from previous studies ${ }^{(2-3,13-15)}$. In the pediatric population, the perception of anxiety also depends on the developmental stage and cognitive potential of the child, since different responses can be observed among those facing the same stressor agent $^{(27)}$.

Children under the age of seven years (pre-school), for example, are able to correlate anxiety with physical symptoms $^{(27)}$. Faced with an imminent surgical procedure, they seek explanations for the situation since they have fears about the surgery(26). As for the older children (students), with more advanced cognitive development, they can get involved in decision-making and their feeling of fear is certainly related to the possibility of being unable to recover from the anesthesia(26). Therefore, the child should be treated and understood individually, taking into account the development stage in which they are, which represents a challenge for professionals and parents who experience the situation. Further researches on preoperative anxiety in children at different stages of the development are desirable.

Regarding the socioeconomic status, evidences reinforce the relationship of this variable with preoperative anxiety in children. However, among the studies found ${ }^{(15-16)}$, in which anxiety was assessed during induction of anesthesia, these associations were not significant.

It is understood that the socioeconomic status may reflect on different physical and psychological conditions among children and hence lead to an ineffective coping with new situations, such as surgery. Furthermore, most children participating in this research belong to the socioeconomic class $C$ and were assisted at a public hospital, where the demand for services and rates of procedures/day/professional are high. This may reduce the supply of individualized care in the preoperative period and hinder the identification of specific health care needs.

Nurses are professionals able to effectively influence the experience of the children ${ }^{(28)}$ and parents ${ }^{(29)}$ in the perioperative environment. It is their responsibility the multidimensional evaluation of the child during their routine work $^{(30)}$, since the psychological, social and economic variables might interfere with proper surgical recovery ${ }^{(31)}$.

In this sense, this study aims to contribute to the advancement of knowledge about anxiety in the period before a pediatric outpatient surgery, emphasizing the 
need for investigations that include the evaluation of this phenomenon throughout the perioperative period. Among its limitations, it is worth mentioning the lack of assessment of parental anxiety, since the presence of anxiety in the child may be related to the high levels of maternal anxiety $(1,15-16,25-26)$.

\section{Conclusion}

The high proportion of children who wait for outpatient surgery experience preoperative anxiety. Age and socioeconomic status influence the occurrence of this phenomenon.

Such findings indicate the need for assessment using a biopsychosocial approach to children, aiming at the proper management of anxiety in the preoperative period, early recovery and reduction of postoperative problems.

\section{References}

1. Fortier MA, Del Rosario AM, Martin SR, Kain ZN. Perioperative anxiety in children. Pediatr Anesth. 2010;20(4):318-22.

2. Kain ZN, Mayes LC, Caldwell-Andrews AA, Karas DE, McClain BC. Preoperative Anxiety, Postoperative Pain, and Behavioral Recovery in Young Children Undergoing Surgery. Pediatrics. 2006;118(2):651-8.

3. Kain ZN, Mayes LC, O'Connor TZ, Cicchetti DV. Preoperative anxiety in children. Predictors and outcomes. Arch Pediatr Adolesc Med. 1996;150(12):1238-45.

4. Chieng YJS, Chan WCS, Liam JLW, Klainin-Yobas P, Wang W, He HG. Exploring influencing factors of postoperative pain in school-age children undergoing elective surgery. J Specialists Pediatr Nurs. 2013;18:243-52.

5. Borsook D, George E, Kussman B, Becerra L. Anesthesia and perioperative stress: Consequences on neural networks and postoperative behaviors. Progress in Neurobiology. 2010;92:601-12.

6. Chorney JM, Tan ET, Martin SR, Fortier MA, Kain ZN. Childrens behaviour in the post-anesthesia care unit: the development of the child behaviour coding systemPACU (CBCS-P). J Pediatr Psychol. 2012;37(3):338-47. 7. Hilly J, Hörlin AL, Kinderf J, Ghez C, Menrath S, Delivet $\mathrm{H}$, et al. Preoperative preparation workshop reduces postoperative maladaptive behavior in children. Paediatr Anaesth. 2015;25(10):990-8.

8. Banchs RJ, Lerman J. Preoperative Anxiety Management, Emergence Delirium, and Postoperative Behavior. Anesthesiol Clin. 2014;32(1):1-23.

9. Pritchard MJ. Identifying and assessing anxiety in preoperative patients. Nurs Stand. 2009;23(51):35-40.
10. Brewer S, Gleditsch SL, Syblik D, Tietjens ME, Vacik HW. Pediatric Anxiety: Child Life Intervention in Day Surgery. J Pediatr Nurs. 2006;21(1):13-22.

11. Lee JH, Jung HK, Lee GG, Kim HY, Park SG, Woo

SC. Effect of behavioral intervention using smartphone application for preoperative anxiety in pediatric patients. Korean J Anesthesiol. 2013;65(6):508-18.

12. Garanhani ML, Valle ERM. O significado da experiência cirúrgica para a criança. Cienc Cuid Saúde 2012; 11(supl):259-66.

13. Al-Jundi $\mathrm{SH}$, Mahmood AJ. Factors affecting preoperative anxiety in children undergoing general anaesthesis for dental rehabilitation. Eur Arch Paediatr Dent. 2010;11(1):32-7.

14. Kim JE, Jo BY, Oh HM, Choi HS, Lee Y. High anxiety, young age and long waits increase the need for preoperative sedatives in children. J Int Med Res. 2012;40(4):1381-9.

15. Davidson AJ, Shrivastava PP, Jamsen K, Huang GH, Czarnecki C, Gibson MA, et al. Risk factors for anxiety at induction of anesthesia in children: a prospective cohort study. Pediatr Anesth 2006;16:919-27.

16. Cagiran E, Sergin D, Deniz MN, Tanattı B, Emiroglu $\mathrm{N}$, Alper I. Effects of sociodemographic factors and maternal anxiety on preoperative anxiety in children. J Int Med Res. 2014;42(2):572-80.

17. Guaratini AA. Estudo da Ansiedade pré-operatória de Yale Modificada: Tradução, estudo de confiabilidade e utilização em crianças de 02 a 07 anos [tese]. São Paulo: Faculdade de Ciências Médicas da Santa Casa de São Paulo; 2006.

18. Associação Brasileira de Empresas de Pesquisa (ABEP). Critério de Classificação Econômica Brasil. 2012 [Internet]. [Acesso 10 fev 2013]. Disponível em: www. abep.org/new/Servicos/Download.aspx?id $=02$

19. Kain ZN, Mayes LC, Cicchetti DV, Bagnall AL, Finley JD, Hofstadter MB. The Yale Preoperative Anxiety Scale: how does it compare with a "gold standard"? Anesth Analg. 1997;85(4):783-8.

20. Hicks CL, von Baeyer CL, Spafforda PA, Korlaarc IV, Goodenoughc B. The Faces Pain Scale-Revised: toward a common metric in pediatric pain measurement. Pain. 2001;93:173-83.

21. Poveda CLEC, Silva JA, Passareli PP, Santos J, Linhares MBM. Faces Pain Scale Revised (FPS-R) - versão em português. 2003. [Internet]. [Acesso $10 \mathrm{fev} \mathrm{2013].}$ Disponível em: http://www.iasp-pain.org/files/Content/ ContentFolders/Resources2/FPSR/Portuguese.pdf

22. Guaratini AA, Marcolino JAM, Teixeira AB, Bernardis RC, Passarelli MLB, Mathias LAST. Estudo Transversal de Ansiedade Pré-Operatória em Crianças: Utilização da Escala de Yale Modificada. Rev Bras Anestesiol. 2006;56(6):591-601. 
23. Cumino DO, Cagno G, Gonçalves VFZ, Wajman DS, Mathias LAST. Impacto do tipo de informação préanestésica sobre a ansiedade dos pais e das crianças. Rev Bras Anestesiol. 2013;63(6):473-82.

24. Weber FS. The influence of playful activities on children's anxiety during the preoperative period at the outpatient surgical center. J Pediatr. (Rio J). 2010;86(3):209-14.

25. Fortier MA, Bunzli E, Walthall J, Olshansky E, Saadat $H$, Santistevan $R$, et al. Web-based tailored intervention for preparation of parents and children for outpatient surgery (WebTIPS): formative evaluation and randomized controlled trial. Anesth Analg. 2015;120(4):915-22.

26. Ghabeli F, Moheb N, Hosseini Nasab SD. Effect of Toys and Preoperative Visit on Reducing Children's Anxiety and their Parents before Surgery and Satisfaction with the Treatment Process. J Caring Sci. 2014;3(1):21-8.

27. Muris $P$, Mayer $B$, Freher NK, Duncan $S$, van den Hout A. Children's internal attributions of anxiety-related physical symptoms: age-related patterns and the role of cognitive development and anxiety sensitivity. Child Psychiatry Hum Dev. 2010;41(5):535-48.

28. Martin SR, Chorney JM, Tan ET, Fortier MA, Blount RL, Wald $\mathrm{SH}$, et al. Changing healthcare providers' behavior during pediatric inductions with an empirically based intervention. Anesthesiology. 2011;115(1):18-27.

29. Delaney D, Bayley EW, Olszewsky P, Gallagher J. Parental Satisfaction With Pediatric Preoperative Assessment and Education in a Presurgical Care Center. J PeriAnesthesia Nurs. 2015;30(4):290-300.

30. Chieng YJ, Chan WC, Klainin-Yobas P, He HG. Perioperative anxiety and postoperative pain in children and adolescents undergoing elective surgical procedures: a quantitative systematic review. J Adv Nurs. $2014 ; 70(2): 243-55$.

31. Smith L, Callery P. Children's accounts of their preoperative information needs. J Clin Nurs. $2005 ; 14: 230-8$.
Received: Feb. 18 2015

Accepted: Nov. 26 2015
Corresponding Author:

Louise Amália de Moura

Universidade Federal de Goiás. Faculdade de Enfermagem.

Rua 227 Qd 68, S/N, Setor Leste Universitário

CEP: 74.605-080, Goiânia, GO, Brasil

E-mail: louisefmtm@yahoo.com.br
Copyright $\odot 2016$ Revista Latino-Americana de Enfermagem This is an Open Access article distributed under the terms of the Creative Commons (CC BY).

This license lets others distribute, remix, tweak, and build upon your work, even commercially, as long as they credit you for the original creation. This is the most accommodating of licenses offered. Recommended for maximum dissemination and use of licensed materials. 